\title{
La reconstrucción gráfica de Yapeyú de Vicente Nadal Mora, un estudio poco conocido (1949)
}

\author{
Francisco Girelli* \\ Daniel Schávelzon**
}

\section{Recibido: 19 de mayo de 2013}

Evaluado: 26 de junio de 2013

La misión de Yapeyú fue durante mucho tiempo una de las menos conocidas de la región jesuítica del noreste argentino, pese a su importancia y a haber sido el sitio de nacimiento del héroe nacional José de San Martín. Esto último produjo un número infinito de referencias, pero poco o casi nada se ha hecho realmente por su estudio sistemático. El sitio quedó literalmente aplastado por las polémicas sobre la Casa Natal y el templete que se le hizo a sabiendas de que no era el lugar preciso en donde naciera el héroe, sino sólo lo único con paredes en pie, y la exaltación apologética del personaje se llevó todo lo escrito. Asimismo la construcción del templete que guarda las supuestas ruinas del sector del convento en que naciera San Martín fue tan polémico que produjo una retracción de los investigadores que prefirieron dedicarse a trabajar en lugares menos problemáticos. De ahí que toda nueva información resulte de interés, más si en la década de 1940 la hizo uno de los mejores dibujantes y a la vez conocedores de la arquitectura colonial, Vicente Nadal Mora ${ }^{1}$.

Ese trabajo de Nadal Mora, por circunstancias que lo excedieron, quedó sumergido en la burocracia del Estado por muchos años, incluso el propio autor nunca lo vio publicado (falleció en 1957). Con los años su hijo Leandro Nadal Mora lo publicó pero con tan mala suerte que el libro en que lo incluyó pasó totalmente desapercibido al grado que muy pocos lo conocen ${ }^{2}$. Se trataba de una antología hecha en 1978 con

\footnotetext{
* Arquitecto, docente de Historia de la Arquitectura FADU-UBA, investigador del Centro de Arqueología Urbana.

** Doctor en restauración de monumentos, investigador principal del CONICET, director del Centro de Arqueología Urbana.

${ }^{1}$ Nacido en Mallorca en 1895, llega a Buenos Aires un año antes del Centenario. De formación en Bellas Artes se destaca su labor como dibujante para distintos estudios hasta incorporarse en 1927 a la Dirección General de Arquitectura del ex Ministerio de Obras Públicas (AAVV, 1973).

${ }^{2}$ El único de los dibujos que tuvo gran difusión fue la reconstrucción del pueblo -a vuelo de pájaro-, imagen que si había sido publicada en vida de Nadal en el artículo del diario La Prensa (Nadal Mora, 1955), y luego por Guillermo Furlong en su libro de las misiones (Furlong, 1962: 188) quien la hizo realmente conocida. Con el tiempo fue apareciendo en diversos trabajos de divulgación, que si bien
} 
motivo del bicentenario del nacimiento de San Martin, una recopilación de trabajos sobre el lugar donde naciera aquel.

¿Cómo un planteo tan interesante no tuvo trascendencia y es prácticamente desconocido entre los historiadores del tema? La explicación radica en que el libro se llamó La gloria de Yapeyú y tiene un retrato de San Martín en la tapa en la clásica tradición escolar del mito al héroe ${ }^{3}$. Quizás si se hubiese llamado La misión de Yapeyú y en su tapa aparecía cualquier imagen de las ruinas o la reproducción de algún grabado jesuítico, su trascendencia habría sido otra. Eso nos impulsa a reeditar el estudio (Fig. 1 a 16), hacer la historia que llevó a ese trabajo y algunas observaciones con notas de la época.

La figura de Nadal Mora es bien conocida en la historiografía de la arquitectura colonial argentina como uno de esos extranjeros que a principios del siglo XX enseñaron a valorar la historia y las artes americanas; que supieron ver en lo exótico un valor que localmente no había sido reconocido ${ }^{4}$. La mayor parte de su trabajo se dedicó al estudio de las tecnologías coloniales y a registrar minuciosos detalles edilicios en todo el territorio argentino. No dudaríamos en afirmar que un trabajo como el que acá se presenta tiene especial relevancia por tratarse de Nadal Mora, quien logro combinar grandiosamente la labor de artista e historiador.

El trabajo que había elaborado Nadal Mora sobre la misión de Yapeyú no se limitaba a una descripción de las ruinas, sino que se abocó a la tarea de hacer una reconstrucción gráfica de los edificios principales del pueblo apoyado en la bibliografía $^{5}$ y una corta serie de lo que llamaban estudios arqueológicos ${ }^{6}$. El conjunto de dibujos publicados no se habían conservado en la familia del artista como tantos otros trabajos que no llegó a editar, sino que su hijo los obtuvo por total casualidad. Narra que un día en el antiguo Ministerio de Obras Públicas, en donde él también trabajaba, reconoció la letra de su padre en unos rollos que estaban apilados en la basura. Se trataba del único registro que existía del trabajo sobre Yapeyú. En dicho ministerio Nadal Mora había trabajado como dibujante desde 1927 en la entonces Dirección General de Arquitectura, y luego, tras hacerse cargo de la Sección Monumentos Históricos durante años, pasó a ser nombrado delegado ante la Comisión Nacional de Monumentos.

\footnotetext{
observaron la falta de sustento histórico de la reconstrucción reconocieron lo valioso de la aproximación de Nadal Mora (Castro, 1965: 133; AAVV, 1978; Maeder y Gutiérrez, 1994: 63-64; Maeder y Gutiérrez, 2009: 92-95; Teruel, Lacarrieu y Jerez, 2003).

${ }^{3}$ Ver apéndice, Figura 19.

${ }^{4}$ Algunos de sus libros más destacados son: Compendio de historia del arte precolombiano de México y Yucatán (1933), Manual de arte ornamental americano autóctono (1935), La arquitectura tradicional de Buenos Aires: 1536-1870 (1942), Estética de la arquitectura colonial y postcolonial Argentina (1946), El azulejo en el Rio de la Plata: Siglo XIX (1949), Monumentos históricos de Misiones: San Ignacio Miní (edición facsimilar 1955), La herrería artística del Buenos Aires antiguo (1957).

${ }^{5}$ Básicamente los libros técnicos o serios con que se contaban eran: Leguizamón, 1915; Zuberbuhler, 1915; Maldonado, 1918; Gómez, 1923; Manzi, 1946. El texto más importante ya que incluía todos los inventarios y documentos antiguos era: Estado Mayor General del Ejército, 1932.

${ }^{6}$ En realidad no se había hecho nunca una excavación, en ese momento entendían que una "observación detallada” ya lo era. Este es uno de los grandes absurdos del proyecto: los cimientos y pisos verdaderos estaban bajo tierra y a nadie se le ocurrió ir a buscarlos; hubo que esperar a 1978 para que se hicieran los primeros estudios arqueológicos. Uno de esos primeros trabajos fue publicado en el número 7 de la revista DANA (Catoggio, 1979).
} 
Sobre el tema jesuítico es bien conocido su libro sobre la misión de San Ignacio Miní donde realizó un importante relevamiento de las ruinas (publicado en 1955 en forma facsimilar). Hacia esos mismos años había publicado también dos artículos sobre el pueblo de Yapeyú y uno sobre la fachada de la iglesia de San Ignacio. Cuando armó el libro de San Ignacio es posible que ya pensara en otro para Yapeyú, considerando que su título comenzaba diciendo Monumentos Históricos de Misiones, lo que casi parecía anunciar una serie. Es muy probable que la idea se frustrara o pospusiera por la difícil difusión que tuvo con el primero.

Nadal Mora realizó un único viaje al territorio de las misiones, del 18 de Julio al 5 de Agosto de 1949 como anotara en su libreta de viaje: “Comisión a Yapeyú y San Ignacio"7 . En el artículo publicado en 1955 en el diario La Prensa (Fig. 17) realizó una crónica de su experiencia en Yapeyú y explicó que el viaje surgió "con motivo de investigaciones en busca de restos arqueológicos para una posible reconstrucción de la antigua misión jesuítica y de su poblado indígena.” La descripción que hizo del pueblo enfatiza el aspecto lúgubre que le produjo y planteó que la "reconstrucción, siquiera fuera en sus partes principales alrededor de la plaza, algo desviada de la actual, sería uno de los más grandes homenajes al Padre de la Patria argentina y sin duda también, un atrayente lugar de peregrinación para los días recordatorios”8.

Tal había sido la tarea que se le encomendó en 1949 en la Sección Monumentos Históricos, el realizar la documentación edilicia para un plan elaborado por la Comisión Nacional de Museos y Monumentos Históricos consistente en mudar la "moderna” ciudad de Yapeyú y reconstruir el histórico pueblo jesuítico, con motivo de las celebraciones de 1950, centenario del fallecimiento de San Martín ${ }^{9}$. En el Boletín de la Comisión del año 1947 se detallan las bases del anteproyecto de ley, presentado el día 10 de Abril y firmado por Aníbal F. Imbert y José Luis Busaniche: "Debemos hacer de Yapeyú un museo de la Patria, recuperando los materiales que aún quedan, transformándolo a su aspecto original de 1778 y trasladando su población actual a un nuevo pueblo" ${ }^{\prime 10}$. Más adelante del mencionado Boletín se detallan las precisiones de la casi demencial tarea de reconstrucción:

"Serian demolidos todos los edificios que componen el pueblo ahora existente, incluso el templete sobre la manzana expropiada treinta años atrás porque no existe prueba alguna documental de que las ruinas que ese edificio guarda sean las de la casa natal del General San Martin, podrían utilizarse todas las piedras y elementos del antiguo pueblo que han sido aprovechados desde mucho tiempo atrás para la construcción de viviendas modernas. Como estas piedras y otros materiales antiguos de Yapeyú no bastarían para reconstruir la iglesia, residencia y el colegio jesuítico, habrá necesidad de echar mano de otros restos de las misiones que todavía existen en La Cruz, Santo Tomé, Corpus, y Loreto, todos los que contribuirán a la obra que se proyecta y servirán para dar carácter de autenticidad y originalidad, al pueblo que ha de restaurarse. Quedarían excluidos los restos de San Ignacio y Santa Ana, por tratarse de ruinas que representan valores arquitectónicos y que no corresponde desintegrar.”

\footnotetext{
${ }^{7}$ Nadal Mora, 1995: VII.

${ }^{8}$ Nadal Mora, 1955.

${ }^{9}$ Schávelzon, 2008: 275.

${ }^{10}$ CNMyMH, 1948: 346. 
Ese criterio de reconstruir un pueblo sin datos científicos, desmantelando los otros que sí eran originales y estaban aún en pié, es una total aberración bajo los criterios de conservación tanto de la época como modernos y nos revela la fortuna de que nunca se llevara a cabo tal intervención. Sin embargo, debe entenderse bajo el famoso "quien ha visto una, las ha visto todas" imperante hacia aquel entonces y que fuera esbozado por Leopoldo Lugones en su libro El Imperio Jesuítico ${ }^{11}$. La Comisión Nacional se encontraba desde 1946 en plena crisis, estaba intervenida militarmente y casi sin actividades generadas por ella. En esa óptica de desconocimiento, de quedar bien con el Presidente Perón y con el proyecto del año Sanmartiniano de 1950, es que surgió esta propuesta sin asidero alguno. Es más, hasta ese momento la Comisión había llevado a cabo una extensa tarea de recuperación patrimonial que incluyó la excavación y restauración de las ruinas de San Ignacio; nada más contrapuesto que esta idea de recrear un fantasioso y sin antecedentes conjunto jesuítico. Asimismo en esos años pocos querían acercarse al tema porque la construcción del templete de las ruinas fue un escándalo de ribetes nacionales en que muchos historiadores quedaron mal parados ${ }^{12}$. Pocos se animaban a una propuesta de este calibre.

Al margen de la casi locura del proyecto de Imbert, un militar de rango medio sin ningún conocimiento del tema, el trabajo de Nadal Mora fue muy interesante. Uno de esos aspectos destacados de la reconstrucción en papel es la iglesia. Apoyado en observaciones cuidadosas de los restos de ese sitio y de los otros, y con diversas fuentes documentales que ya habían publicado los historiadores en base al tema de San Martín, complementó su trabajo mediante un profundo estudio de referentes tipológicos. Así, el detallado dibujo de la fachada nos remite a los grabados de las iglesias de Itapúa y Candelaria, aunque por sus proporciones y la articulación de los órdenes se asemeja mucho más al primer caso. Hacia el interior del templo se destaca la resolución de las arquerías que dividen las naves y la presencia del coro en los pies de la iglesia tal cual se daba en San Ignacio Guazú. Es muy llamativa también la presencia del presbiterio, de menor altura que la iglesia, y que remata en un ábside semicircular. Nadal Mora demuestra un hábil manejo del lenguaje jesuítico-guaraní en esos y en otros detalles.

${ }^{11}$ Lugones, 1904.

${ }^{12}$ Magaz y Schávelzon, 1995. 


\section{FACSIMILARES:}

\section{FIGURA 1}

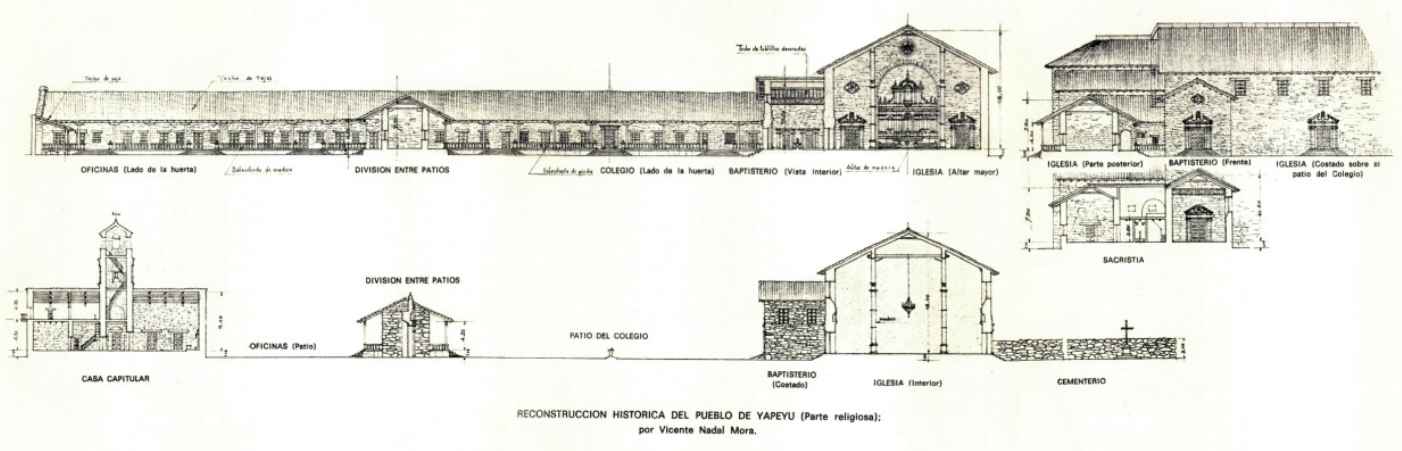

FIGURA 2

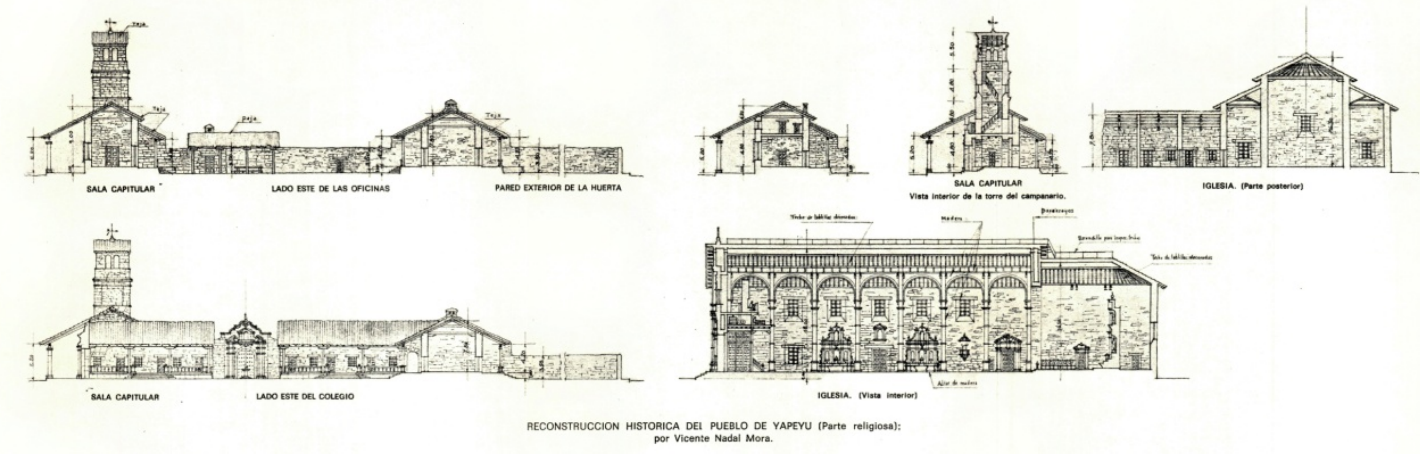


FIGURA 3

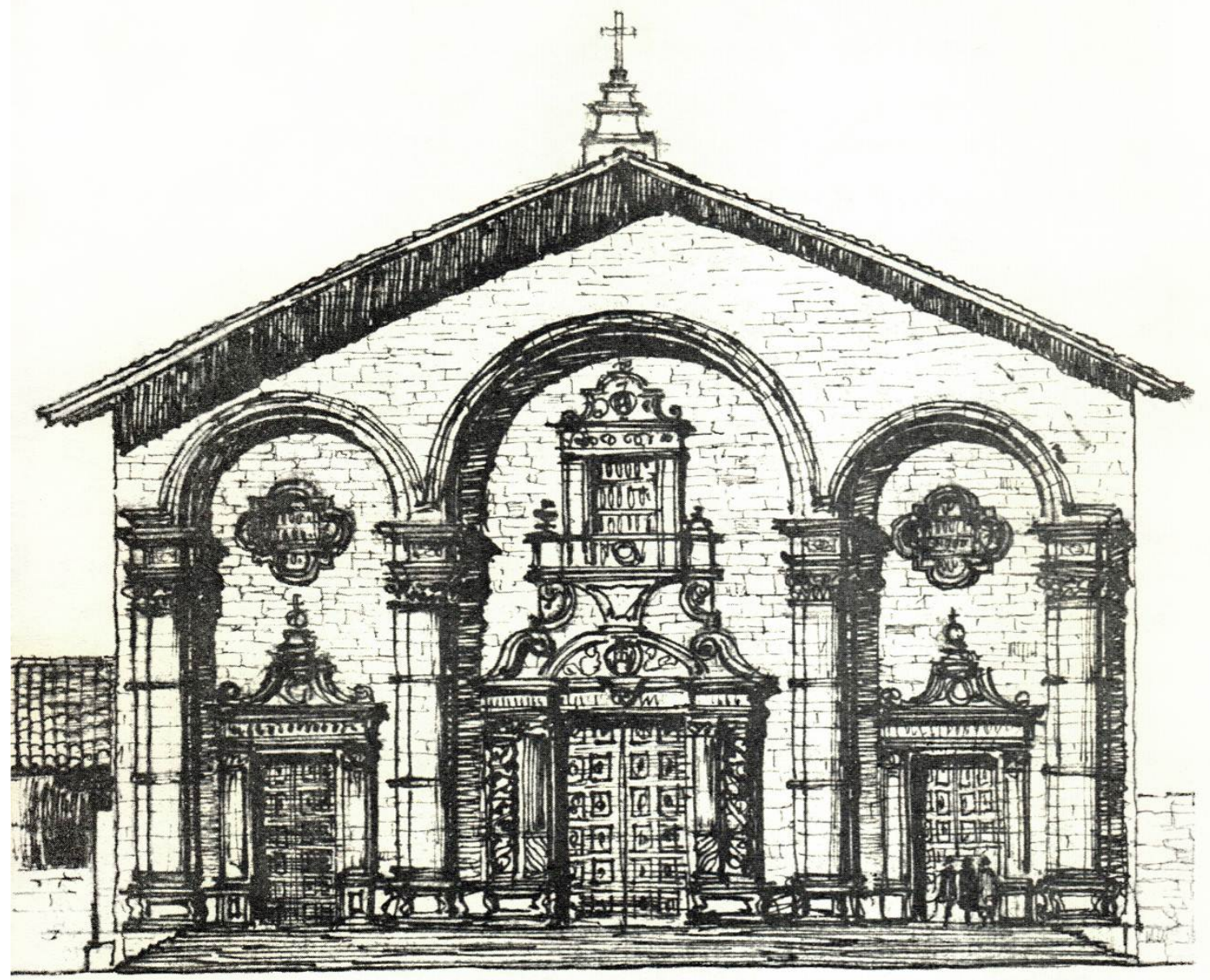

RECONSTRUCCION HISTORICA DE LA FACHADA

DE LA IGLESIA DE NUESTRA SEÑORA DE LOS REYES MAGOS DE YAPEYU; por Vicente Nadal Mora. 
FIGURA 4

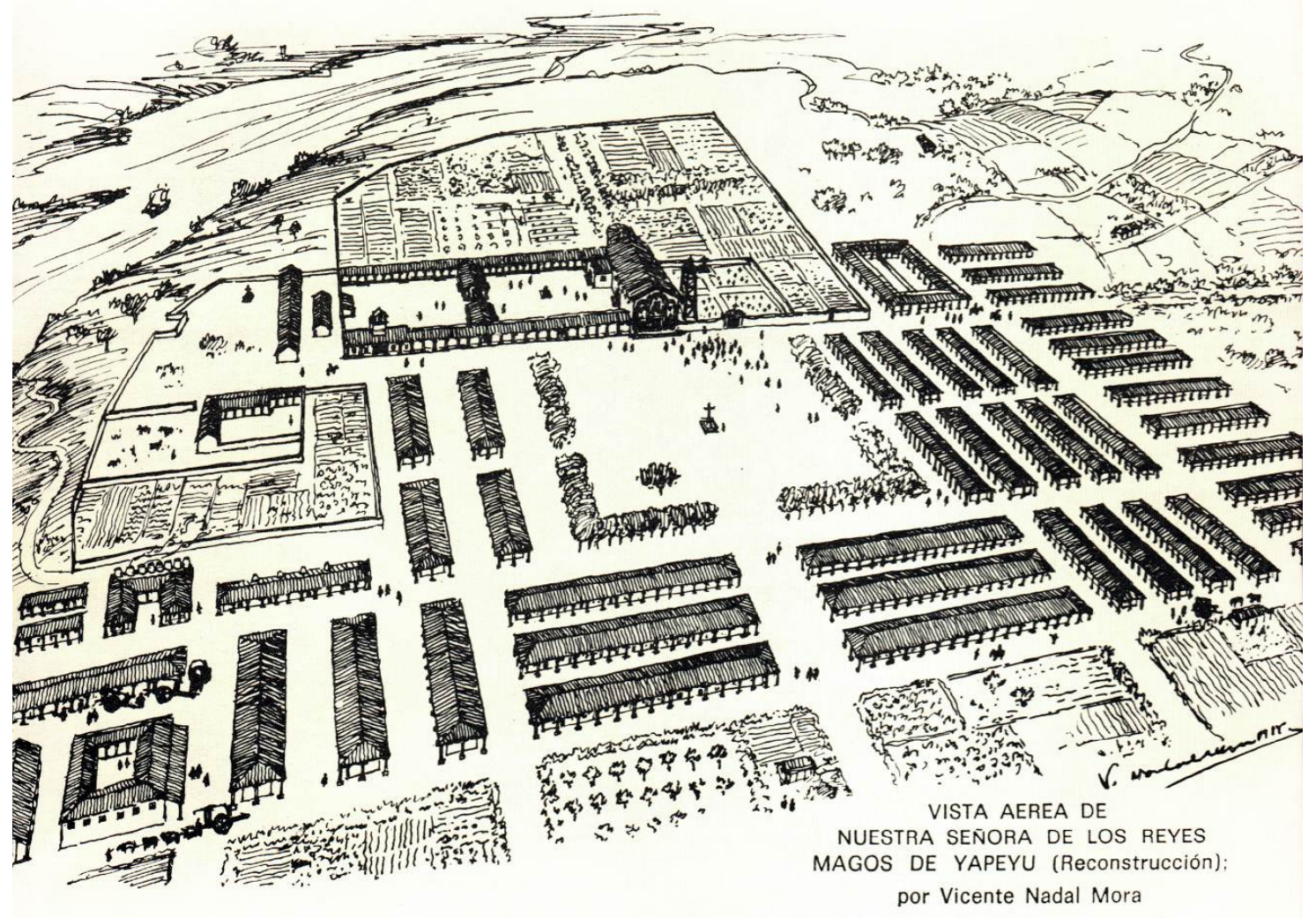


FIGURA 5

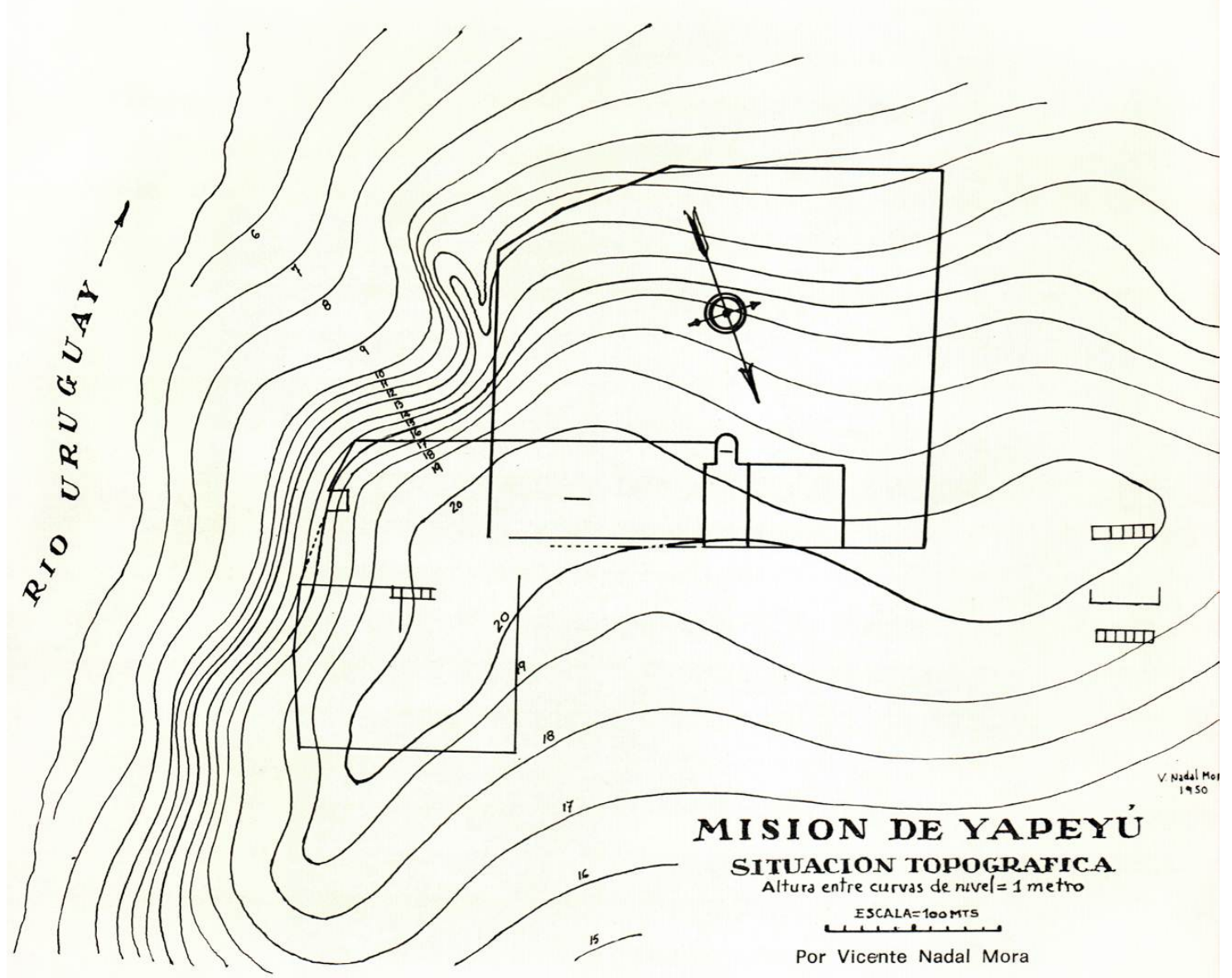


FIGURA 6

\title{
ESTUDIO SOBRE YAPEYU
}

\author{
Por VICENTE NADAL MORA
}

Para poder estudiar debidamente las ruinas de este pueblo, será necesario explicar previamente cómo eran o estaban urbanizados los poblados misioneros durante el siglo XVIII. Se ha escrito que "la Disposición de los pueblos es tan igual y uniforme, que visto uno, se puede decir que se han visto todos ... que los que viajan por ellos, llegan a persuadirse que un pueblo encantado les acompana por todas partes... Es, pues, la figura de todos rectangular, las calles tendidas de Norte a Sur, y de Este a Oeste, y con la plaza, que es bastante capaz y llana, en el centro: ocupando el testero principal que mira al septentrión la Iglesia con el colegio, y cementerio a sus lados... El resto de la población se reduce a puras isletas cuadrilongas de 80 a 100 varas de frente, y en ellas están repartidas las casas de los particulares, guarnecidas de su portal o tinglado corrido, que las guarda de los soles y aguas" ( $\left.{ }^{1}\right)$.

Esta es en efecto la disposición que podríamos llamar fundamen. tal en cuanto a la Iglesia, Colegio, cementerio y forma de las viviendas de los naturales, no en cuanto a la identidad de aspecto, que pudiera ser tanta como para confundirse unos pueblos con otros.

En todos los casos, la Iglesia suele indicar el origen urbanístico del pueblo, situada en el eje de la plaza, con más o menos exactitud, y en el eje también de la calle principal de acceso a la misión. La plaza es vasta y aproximadamente cuadrada, limitada por tres de sus lados por viviendas alargadas y porticadas con sus frentes longitudinales mi. rando al ámbito; el otro lado lo ocupan en continuidad indisoluble y en una gran extensión la Iglesia, teniendo a un lado el colegio y los talleres, al otro el cementerio, y detrás de todo ello la huerta. Aquí

(1) Diego de Alvear "Relación Geográfica e Histórica de la Provincia de Misiones", Bs. As., 1836. 
FIGURA 7

se ofrecen ya variantes importantes de disposición general, como podemos por ejemplo verlo en las plantas de la Misión de San Borja en que de derecha a izquierda se suceden los talleres u oficinas, el colegio, la Iglesia y el cementerio, ocupando por detrás todo el conjunto la huerta rigurosamente rectangular; en la Misión de Candelaria y San Ignacio Miní, en cambio, se invierte el orden, empezando por el cementerio, la iglesia, el colegio y los talleres, ocupando también la huerta toda la parte posterior. (Ver ilustración en esta obra).

La huella de las ruinas de Yapeyú sigue la disposición de las Misiones de San Ignacio y Candelaria, mostrando, siempre de derecha a izquierda, el cementerio, la iglesia, el colegio y los talleres, ocupando la huerta posterior algo más que el largo total de todo lo anterior.

Veamos ahora también la disposición de los poblados, como para apreciar que existían sensibles diferencias de trazado y magnitud entre eilos. Volviendo a los planos anteriores notaremos como San Borja tiene 9 viviendas o isletas de la que 4 solo cierran la plaza; Candelaria se compone de 52 isletas dispuestas en 4 filas de 7 edificios y 3 filas de 8 edificios, San Ignacio cuenta con 50 isletas distribuidas en 4 filas de 4 , y 7 de $6\left(^{2}\right)$. Yapeyú nos ofrecería, según las descripciones y hasta tanto no se investigue debidamente, 39 isletas.

Vemos, pues, cómo estos pueblos ofrecían notables diferencias como para no poder ser unificados en su aspecto. Tampoco lo serían en su arquitectura, pues basta comparar las fachadas de las iglesias de Candelaria, Trinidad y San Ignacio, para apreciar las profundas diferencias entre ellas. Tan solo los edificios o isletas de los naturales podrían parecer semejantes en sí mismos por su arquitectura de pórticos de madera repetidos en toda las misiones. Además de las viviendas de los indigenas, había en aquellos pueblos otras de carácter común, tales como la gran cocina popular, la tahona, los talleres diversos, de carpintería, herreria, carretería, graneros, depósitos, etc. Había también un hospital, un alojamiento para mujeres viudas o abandonadas, una cárcel. Nada dicen las descripciones de los servicios sanitarios que no se ven tampoco en las plantas y ruinas conocidas. ¿Serian tal vez locales colectivos como los usados por los antiguos romanos?

Teniendo por base este conocimiento general de los pueblos misioneros, analizaremos ahora, detalladamente, cómo pudieron ser los edificios de Yapeyú durante la decimooctava centuria, para lo que dividiremos el estudio en dos partes: una referente al conjunto religioso y otra al poblado o parte civil.

(2) En las ruinas se han encontrado trazos de sólo 34 isletas y otros 3 edificios mayores. 
FIGURA 8

\section{EL CONJUNTO RELIGIOSO DE YAPEYU}

La topografía del terreno en el lugar que ocupó la misión yapeyuense, ofrece la forma de continuidad de ondulaciones suaves que bajan en fuerte declive a las aguas del Río Uruguay, el que frente al pueblo está dividido por una isla alargada y baja. Examinando las curvas de nivel notaremos cómo la cima de una meseta determinó la situación ideal de la planta religiosa; la extensa fachada quedaba así sobre un terreno totalmente horizontal. En un plano de relevamiento de cimientos levantado en 1915 por la Oficina de Tierras y Obras Públicas de la Provincia de Corrientes, vemos claramente el típico ordenamiento del cementerio, la iglesia y el rectángulo que ocupaba verosímilmente el colegio y los talleres, y al fondo el solar de la huerta, inmensa como en todas las misiones (Ver vista aérea). Las dimensiones máximas del conjunto son aproximadamente de $245 \mathrm{mts}$. en el frente principal y de $225 \mathrm{mts}$. de profundidad. En otro plano, esquemático, que inserta el P. Maldonado en su conocida obra sobre Yapeyú (Ver Ilustración) se indica la distribución de los diversos locales interiores de la parte religiosa. Se pueden ver también en dicho plano otros edificios aislados, tales como un horno de fundición, una reclusión, cárcel, la casa natal de San Martín, un murallón ribereño; aparece también indicado un sótano o subterráneo que desde la barranca del Río conduce bajo la iglesia y se bifurca hacia la plaza.

Es de notar que en ninguno de estos planos se da conocimiento del trazado de la población indígena. Sin embargo los restos de 3 edificios, al Oeste o Norte de la huerta, cuya planta alargada y dividida en recintos continuos reproduce la típica vivienda indígena de las misiones. constituye un importante indicio para poder deducir parte del poblado.

Pasamos ahora a analizar cada uno de los componentes de la parte religiosa tratando de reconstruirlos de acuerdo a los informes y planos que poseemos, y siguiendo el orden correlativo de su situación respectiva.

Cementerio: Según los cimientos formaba éste un rectángulo cuyas dimensiones eran aproximadamente de $55 \mathrm{mts}$. sobre la calle y 47 de fondo; por los lados O y S lo rodeaba la huerta teniendo al E el muro de la iglesia. El plano de la obra del P. Maldonado señala en este recinto una torre, que sería el campanario; en la vista antigua de la misión de Candelaria (Ver Ilustración) puede verse esta misma situación del campanario; sin embargo un inventario del año 1802 da cuenta de que contiguo a la iglesia provisional que existía en esa época, se hallaba "un campanario nuevo de madera fabricado en este año a 
FIGURA 9

su inmediación con otras piezas, en el 2do. patio del Colegio (Ver Capítulo XIX), lo que hace creer que la susodicha torre estuvo situada antes en el patio del Colegio (como en San Ignacio Miní) y fue reconstruida en el recinto del camposanto (como indica el plano del P. Maldonado y el de Candelaria). El aspecto del campanario podemos suponerlo como el de Candelaria, a falta hasta ahora de otras imágenes, construido en forma de un entramado de madera con escalera de tramos rectos hasta el último cuerpo, que contenía, según se dice, $5 \mathrm{cam}$ panas de diferentes tamaños y terminaba "coronada por el doble símbolo de la redención y de la orden" $\left({ }^{3}\right)$. La entrada al cementerio era primeramente muy sencilla y se demolió para levantar otra $\left(^{4}\right)$ : aquel fragmento pétreo de arcada de puerta, maravillosamente en equilibrio sobre su endeble base de piedras comidas por la intemperie $\left.{ }^{5}\right)$. Por otra puerta se comunicaba este recinto con la iglesia, y al fondo se hallaba la antisacristía de la misma y es muy probable que existiera también una galería adosada a la iglesia, como en otras misiones. Estaba dividido en cuarteles con calles bordeadas de nardos; cada sepultura tenía una lápida (probablemente escrita en guaraní, como las varias que se conservan), al fondo había una gran cruz; algunos naranjos debían dar también sombra al cementerio.

Iglesia: Su inauguración habríase efectuado el día sábado anterior al de la Resurrección, del año de 1643, siendo de maderas transportada de lugares distantes; hubo que restaurarla en 1649, teniendo entonces un sagrario dorado con imágenes $\left.{ }^{6}\right)$. Un inventario del año 1768 hace saber que poseía 5 altares con retablo, y 4 confesionarios, órgano y púlpito, y en el bautisterio una pila de piedra. En 1784 la afecta seriamente un incendio, hallándose ruinosa en 1798 y a punto de caerse al año siguiente. En 1800 sigue amenazando ruina; en 1801 se habla ya de un galpón que sirve de iglesia de 40 varas de longitud, cubierto con paja (Ver Capítulo XIX). La planta de los cimientos descubiertos demuestra un recinto de $45 \times 23$ mts. aproximadamente, sin el aditamiento posterior de un profundo ábside, extraño por su fondo semicircular, forma fuera de lo común en las iglesias misioneras; este ábside no figura en el esquema que presenta el P. Maldonado en su obra. Por razones litúrgicas y de simetría de planta, debió existir la sacristía y antisacristía, ninguna de éstas muestra el plano de cimientos y sí la antisacristía dentro del cementerio señala el plano del P. Maldonado.

(3) M. Leguizamón "La casa Natal de San Martín". Buenos Aires, 1915, Pág. 54

(4) Legajo Compañía de Jesús ("Se demolió la puerta que tiene el cementerio hacia la plaza

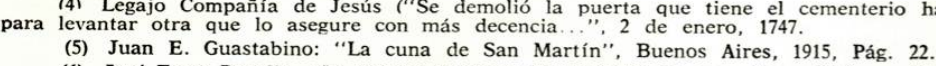
(6) José Torre Revello, "La Iglesia de Yapeyú" (inédito), Buenos Aires, 1949, gentileza del autor. 
FIGURA 10

En una carta (1880) se menciona un sótano que existía en la iglesia en escombros $\left({ }^{7}\right)$ que bien pudiera referirse a una cripta. La iglesia de Yapeyú debió ser de 3 naves, con cubierta a dos aguas. Las columnas interiores es de suponer que fueran de grandes troncos de madera, escuadrados debidamente, como indican lo fueron en otras iglesias similares. Según investigaciones de un estudioso del Yapeyú jesuítico $\left.{ }^{(}\right)$, las columnas de las naves fueron doradas y jaspeadas, con sus buenos remates y molduras de arco a arco, con figuras pintadas en los huecos de ellos; esta descripción está conforme con el aspecto interior que tenía la iglesia quemada de San Ignacio Guazú, con pilastras de maderas y arcadas entre ellas; siguiendo el estudio de dicho autor, tenía media naranja en el crucero. Dada la planta rigurosamente rectangular que indican los cimientos, bien pudo ser la mencionada media naranja una cúpula de poco peralte, bajo la cubierta uniforme exterior, como en la iglesia franciscana de San Francisco de Santa Fe. También no es aventurado suponer por correlación, que el techo fuera del llamado "de alfarje" o "a par y nudillo", como existe en la iglesia santafesina y lo tenía también la mencionada de la misión de San Ignacio Guazú. Por la división interna en tres naves, necesariamente debía poseer la iglesia yapeyuense también tres puertas en su imafronte, de las que la central se dice era de cedro tallado y más ancha que las laterales (Ver Antonio Monzón). También es natural que hubiere dos puertas más laterales, una al cementerio y otra al colegio. El bautisterio que era un recinto con categoria de capilla por su riqueza decorativa, se comunicaba con la iglesia y con el patio del colegio, teniendo en el centro la pila bautismal. El piso de la iglesia era de baldosas octogonales y cuadradas formando red, cuyos restos se han encontrado, asentadas directamente sobre la tierra firme $\left({ }^{9}\right)$. En las excavaciones se hallaron también restos quemados de la tirantería del techo, tejuelas y tejas rotas. Los muros, de 1,50 mts. de espesor, se encontraron construidos con tierra apisonada. (Ver Capítulo VI de esta obra).

Colegio, Talleres y Cabildo: Contiguo a la iglesia, los cimientos cierran un rectángulo de unos 120 × $55 \mathrm{mts}$. aproximadamente. Este recinto se halla retirado con respecto al plano del imafronte de la iglesia, dejando un espacio, evidentemente correspondiente a una desaparecida galería, de la que se reconocen 11 pilares distanciados a unos $5 \mathrm{mts}$. de eje a eje. Esta galería es típica de las otras misiones, según puede apreciarse en los documentos que de ellas se poseen. Dentro de

(7) M. Leguizamón, "La casa Natal de San Martín", obra citada, Pág. 21.

(8) Antonio Monzón, trabajo inédito.

(9) H. F. Gómez, "Yapeyú y San Martín", Bs. As., 1923, Pág. 95 y 204. 
FIGURA 11

este vasto rectángulo habrá pues que ubicar el colegio y los talleres a continuación, según las descripciones de ellos conocidas. El esquema de la obra citada del P. Maldonado, no indica más que el colegio compuesto de 13 aposentos alrededor de un patio porticado por tres lados y en él la sacristía de la iglesia. Don Juan de San Martín, en un inventario de entrega a Don Simón de Soroa, a los 17 días del mes de enero del año 1780 (Ver Capítulo XIX), menciona para las "Casas Principales" (se sobreentiende el Colegio jesuítico abandonado) una lista de 16 cuartos - a continuación coloca una "Noticia de lo que se encuentra en otras habitaciones del $2^{\circ}$ Patio y oficinas que se hallan en él" en total 9 cuartos más- pasando luego a describirse lo que se encuentra fuera de las "Casas Principales" de lo que nos ocuparemos luego. Se detalla también en este documento, cómo las Casas principales se componían de un patio grande, y en el corredor principal, tiene 9 cuartos que miran de Norte a Sur, con sus puertas y ventanas con vidrieras; y de Este a Oeste seis cuartos con sus puertas y ventanas sin vidrieras, y en medio del Patio un Quadrante de una columna de Piedra pulidamente labrada, de vara y media de Alto...". En 1799 se mencionan los "Edificios de la Casa Principal nominadas Colexio que se compone de primero y segundo patio y en ellos veinte y siete quartos siendos los del segundo patio quasi inabitables por amenazar ruinas y contiguo al primero la Iglesia que esta amenazando Ruina". Hay pues una diferencia de dos cuartos con el anterior inventario.

Los 9 cuartos mirando al Sur del primer patio tenían 5,50 x 7,00 mts. o $6,00 \times 6,00 \mathrm{mts}$., según diversos autores, con paredes de piedra blanqueadas, piso de ladrillos cocidos, argollas para colgar hamacas; estos 9 cuartos, ya hemos visto, tenían puertas y ventanas vidrieras, presumiblemente 1 puerta y 1 ventana dando a las galerías que habían en el patio y en la huerta. Los seis restantes cuartos, de Este a Oeste, eran por lo tanto transversales al patio y se dividían en dos cuerpos, y con puertas y ventanas sin vidrios, como también ya se ha indicado. Una portada entre ambos cuerpos debía comunicar uno y otro patio.

El destino y moblaje de cada uno de los aposentos se halla especificado en el mencionado inventarig del año 1780 y también en el de 1798 (Ver Capítulo XIX). Allí vemos como en el primer cuarto vivía el Padre cura y contenía unos pocos muebles, el segundo era un dormitorio o celda con dos catres, varias sillas, una mesa, etc., el $3^{\circ}$ otra habitación con sillas diversas, 2 catres, 1 mesa con estantes, cortinas en las puertas y ventanas, el $4^{\circ}$ también otra habitación, con una mesa, cuadros y espejo, el $5^{\circ}$ que en el inventario de 1780 , parece ser un despacho importante por su contenido, 12 sillas con Asientos y Espaldares de 
FIGURA 12

Baqueta, cortinados, cuadros y láminas con marcos dorados, un espejo con marco de cristal, cuatro mesas, etc.; es efectivamente designado en el de 1798 como "habitación del señor Teniente Gobernador"; el 6? cuarto parece haber sido un dormitorio, pues contenía una cuja con colchón y almohada y diversos otros muebles y objetos, entre éstos un reloj despertador; el $7^{\circ}$ cuarto debió ser un dormitorio para varias personas, pues contenía tres catres, sillas y una mesa; el $8^{\circ}$ cuarto tenía otro catre, una silla y un banco largo; por ứltimo completaba la serie de 9 cuartos de Oeste a Este, otro local indicado como "refectorio" con una mesa grande de tablones y otra redonda, unas sillas y dos bancos largos cubiertos, platos, manteles, cuadros, etc. Los 6 cuartos restantes, transversales al patio, de Norte a Sur p estaban separados en dos cuerpos de 3 locales cada uno, con una portada entre ellos y que comunicaba el primero con el segundo patio, siendo cuartos con puertas y ventanas sin vidrios. Siguiendo la numeración correlativamente, en el orden seguido de Oeste a Este y de Norte a Sur, es decir contorneando el patio del colegio, nos encontramos con que el $10^{\circ}$ cuarto tenía un destino incierto pues contenía dos mesas y un colchón; el 11\% era la armería, con fusiles, carabinas, alabardas, etc.; el $12^{\circ}$. estaba destinado a botica con diversidad de frascos y cajas; el 13ㅇ era la escuela con una mesa y bancos, el 14\% un cuarto de música, sin indicar su contenido, y el 15\% la mayordomía o guardarropas, donde se guardaban los vestidos para uso del cabildo y danzas.

Estos cuartos que rodeaban el primer patio por dos lados, tenían galería de 2,50 de ancho, con piso de baldosas a una altura de 1,00 m. sobre el nivel del patio. No poseemos más detalles de estas galerías, pero podemos suponerlas como las del Patio de San Ignacio Miní, con balaustradas y escalinatas de piedra, pilares de madera y techo de tejas. El patio estaba embaldosado y en su centro se hallaba "un Quadrante de una columna de piedra pulidamente labrada, de vara y media de Alto..." (Ver Inventario de 1780). En sus investigaciones por el pueblo actual el autor de estas líneas pudo encontrar una piedra labrada con un cuadrante solar, que es de suponer pertenecía a la columna citada (véase en los planos reproducidos en esta obra). Este patio, como el siguiente, debían desaguar por canalizaciones semejantes a las de otras misiones.

En el segundo patio, también embaldosado, se veían otros 9 cuartos enfilados de Este a Oeste, a continuación de los 9 primeramente descriptos. Estos recintos serían, siguiendo un mis̉mo inventario, y en el siguiente orden; la platería, Herrería, Carpintería, Tornería, Rosariería, Zapatería, Telares, Panadería y Cocina. 
FIGURA 13

El Cabildo de acuerdo con el inveritario de 1780, estaba fuera de las casas principales. H. F. Gómez supone que tal vez sirvió de iglesia provisional. Según Monzón este edificio capitular está techado con tejas y tenía corredores a ambos lados, en uno de los cuales se hallaban 4 pequeños cañones; las ventanas llevaban rejas de hierro. La cárcel, "Guardia cárcel" dice un inventario (muy posiblemente tan solo algún calabozo, ya que como cárcel propiamente se edificaba en aquellas misiones un edificio propio) se hallaba de Este a Oeste, este mismo autor ha averiguado que la cárcel poseía 8 pares de grillos y tres grilletes $\left({ }^{10}\right)$, un recinto con techo de paja, construido a poca distancia del Cabildo servía de comedor a los presos. Se conoce también cómo estaba amueblada la Sala Capitular, la que presidía un retrato del rey, en las paredes se veían diversas banderas y gallardetes, la mesa estaba cubierta con tafetán carmesí, varias sillas diferentes, escaños y armarios completaban el moblaje de la sala.

Huerta: El P. Maldonado señala para la huerta un recinto irregular cerrado en curva, evidentemente como indicación sumaria o, aproximada de su área; dentro de este recinto sitúa, como ya hemos visto, la cárcel, y además, mirando al río, a continuación de los talleres, unos hornos de fundición, una fila de 8 celdas y un sepulcro aislado. Los cimientos descubiertos del muro de la huerta, encierran un vasto cuadrilátero, cuyo lado posterior se curva siguiendo aproximadamente la curva de nivel del terreno en pendiente hacia el río. Los inventarios no hablan de ningún edificio dentro de la huerta, y sí de un variado conjunto de flores y frutales. Los hornos, las celdas y el sepulcro citados, vendrían a quedar dentro del espacio cerrado al sur por un largo cimiento de muro, que es prolongación precisamente, del cimiento sur del cuadrilátero del colegio y los talleres, desde el que empieza la huerta.

Pueblo: Debemos volver nuevamente al inventario del año 1780 para tener noticias del cómo estaba constituido el pueblo indígena; este inventario nos informa que "las viviendas de los Naturales del Pueblo se componen de treinta y nueve ceras de Casas, todas techadas de Teja". El inventario del año 1798 señala solamente "18 filas de casas que componen el pueblo amenasando ruina...". En el año de 1802 se menciona "El Pueblo enteramente, arruinado en sus edificios...". Las 18 hileras de casas siguen inventariados hasta el año 1805. (10) Maldonado sitúa la cárcel detrás y en el eje de la iglesia, dentro de la huerta, ubicación
al parecer inverosímil (Véase plano inserto en esta obra).

$$
-331-
$$


FIGURA 14

Se han descubierto, y quedan aún (1950) ruinas de las casas, los cimientos de 3 de estas hileras, contiguas unas a otras en el lado Oeste del recinto religioso; una de estas filas muestra sólo sus cimientos perimetrales de tres de sus lados; las otras dos son casas de 5 y 6 locales enfilados; es todo cuanto se conoce hoy gráficamente con certeza de lo que fue del pueblo, sin contar con las ruinas de la casa natal del Gri. San Martín, descripta en el inventario de 1780 como: "Una Cera de Casas que mira de Norte a Sur, con nueve quartos y una sala, y con sus corredores de una Banda, y otra, y techado de buenas maderas, con sus Bentanas y Puertas con sus cerraduras y llaves todo nuevo, y todas las Bentanas con rejas de fierro y las Paredes de Piedra, y lo mismo la del Corral que circula todo el ámbito de dicha Cera de Casas".

De cómo estaban distribuidas aquellas 39 Ceras o isletas, no poseemos datos; los restos citados podrían ser, sin embargo, un indicio probable de una de las series de casas paralelas, sin poder determinar el número de ellas en tal orientación. Es de suponer que la plaza, de unos $120 \mathrm{mts}$. de lado y situada frente a la iglesia, estuviera rodeada de 6 filas de casas, con sus pórticos o soportales mirando a ella, como en los demás pueblos misioneros. Luego, cada fila de casas, separadas por calles cuyos ejes se iniciarían en el eje de la plaza, nos señala indudablemente la disposición de los grupos respectivos.

De Moussy (11) nos informa que las casas que rodeaban la plaza, cuyas ruinas se conservaban aún al tiempo de su viaje, estaba resguardada por una doble galería sostenida por pilares de urunday, apoyada sobre unos cubos de piedra roja bien labrados; alguno de estos pilares y cubas estaban en su lugar, pero otros habían sido destruidos y sus restos yacían diseminados. Iguales noticias nos proporciona, referente a aquellas casas Juan Pedro Gay ${\left({ }^{12}\right)}^{2}$ al hablar de la misión de Yapeyú. Al citar De Moussy una doble galería se refería, creemos, de una galería a uno y otro lado de las casas, y no a dos pisos de galería, como algunos traductores suponen. Los inventarios, como hemos ya visto, nos dicen que dichas casas eran de piedra y techadas con tejas y dan ciertos detalles de su carpintería de puertas y ventanas; habla también de un corral todo alrededor, presumiblemente la galería circundante. Villegas (13) agrega que las casas de los indigenas estaban subdivididas por tabiques y sus pisos eran de ladrillo. Hernán F. Gómez $\left({ }^{14}\right)$ indica

(11) Martín de Moussy. Memoria histórica sobre la decadencia de las ruinas de las misiones jesuiticas, traducción por J. L. Busaniche en el Boletín de la Comisión de Museos y Lugares Histó. cos No X. Año 1948, Pág. 151 y siguiente.

(12) Juan Pedro Gay. Historia de la República Jesuítica del Paraguay. Año 1861, Pág. (13)

43. Alfredo G. Villegas, "Juan de San Martín. El Padre de un Libertador". Santa Fe, 1948.

(14) Obra citada, Pág. 96. 
FIGURA 15

que las casas indígenas formaban una gran pieza dividida por tabiques de cuero, cosa también común en otros lugares del Paraguay antiguo. El P. Hernández ${ }^{(15)}$ dice que cada casa era un aposento sin alcoba, cocina, ni retrete, y que las casas más grandes y areadas y con soportales más anchos se hallaban, en aquellos pueblos misioneros, alrededor de las plazas. Se dice que las únicas casas con divisiones interiores de piedra eran las que estaban junto a la plaza, destinadas a los caciques, mientras que las demás lo estarían con tabiques de cuero, algo contradictorio en general esto, por cuanto las ruinas descubiertas de casas alejadas de la plaza muestran cimientos de muros interiores.

Podemos, pues, suponer estas casas del pueblo indígena, con pabellones alargados, rodeadas por sus cuatro lados por una galería formada por pilares de madera dura, apoyadas sobre cubos de piedra de la región $\left({ }^{16}\right)$, a diferencia de lo que muestran las ruinas de las casas de la misión de San Ignacio Miní, cuyas galerías están formadas por pilares de piedra de sillería... El techo de estas viviendas, de tejas, no sabemos si fueron a dos aguas como en San Ignacio, o a cuatro como en Candelaria. Nada podemos decir tampoco del aspecto y planta del hospital, almacenes, talleres para la construcción de tejas, carretas, astillero, etc. Monzón nos informa que la cocina popular contenía 14 ollas, y las correspondientes parrillas y asadores, y que en la cárcel había 8 pares de grillos y tres grilletes.

Más positivos son los datos que poseemos de la casa natal del Gral. San Martín. Sus restos constituyen un documento viviente que nos muestra el modo de construir en los tiempos del viejo pueblo desaparecido. Maldonado nos indica en su conocido plano (Ver Ilustración), una distribución de 10 cuartos en fila y formando "L" alrededor de dos lados de un patio rectangular. El Ing. V. Pérez Díaz levantó en 1908 un plano en el cual nos precisa cuatro de aquellas habitaciones y continuación de otras (Ver Ilustración). En este plano se indican las dimensiones de alguna abertura y un alzado de la casa, con techo a dos aguas y un pequeño nicho interior muy elevado del suelo. También poseemos otro plano levantado por el Arq. R. Villemint en mayo de 1915 el cual sólo nos muestra ya una sola habitación y restos de otras tres; el alzado en este plano nos indica cómo era de baja dicha vivienda, con sólo 3,40 mts. de altura en la parte más alta de su pared transversal que señala la doble pendiente del techo. En esta misma época se publicaron también fotografías del estado de dicha casa ( $\left.{ }^{17}\right)$

(15) Pablo Hernández, S. J., "Misiones del Paraguay", Tomo I. Barcelona, 1913 (16) El autor no ha podido encontrar entre la cantidad de piedras existentes, ninguna que
hubiera podido servir para apoyo de aquellos pilares ya que verosímilmente tales cubos debieron tener
un hueco superior para empotramiento de la madera un hueco superior para empotramiento de la madera.

(17) "Caras y Caretas", Agosto 21 de 1915.

$$
-337-
$$


FIGURA 16

otras más antiguas aún muestran la casa destechada, pero más completa $\left({ }^{18}\right)$. El piso de esta casa estaba compuesto con baldosas de tierra cocida octogonales de $202 \mathrm{~mm}$. en diámetro interno del octógono combinadas con otras cuadradas de $84 \mathrm{~mm}$. por lado formando red; estas baldosas tenían $30 \mathrm{~mm}$. de espesor. Suponemos que esta casa no difería de las del resto de la población en su galería, ventanas con rejas, puertas, etc. Sus ruinas, encerradas hoy dentro del templete, son imponentes por sus enormes paredes de un aparejo sumamente rústico.

Restos: Recorriendo el actual pueblo de Yapeyú, es fácil ver como quedan aún numerosas piedras antiguas labradas, aprovechadas en las viviendas modernas, ya de modo aislado convertidas en asiento ante las puertas, como losas de pisos y frecuentemente sobrepuestas formando aparejo, o simplemente amontonadas en desorden al fondo de los terrenos baldíos de algunas propiedades. Tales piedras se hallan así diseminadas no sólo en las propiedades centrales del pueblo de Yapeyú, sino también en las viviendas considerablemente alejadas de la plaza y aún en el cementerio.

En la búsqueda de restos arqueológicos que emprendió el autor de estas líneas, el más valioso hallazgo fue efectuado en una casa situada en los airededores del pueblo, donde aprovechada como baldosa en el suelo de una galería, se hallaba una piedra labrada en forma cuadrante solar, presumiblemente el que perteneciera a la misión $\left({ }^{19}\right)$; formaba una loseta cuadrada de $4 \mathrm{~cm}$. de espesor y 30 de lado, de corte rústico en su cara posterior y en los bordes; en su frente, recuadrado, se veía el típico trazado astronómico de 10 líneas incisas convergentes al semicírculo central inferior; interrogados los viejos moradores de la casa, manifestaron que tenían a dicha piedra como un recuerdo familiar, y que durante toda su vida recordaban haberla visto en su vivienda.

Existen otras piedras, molduradas en poco relieve, la mayoría cúbicas, como si hubieran servido de basas o sillares de pilastras exentas; muchas de estas piedras repiten el mismo tipo de molduración y son además de idénticas dimensiones; se caracterizan por llevar varias fajas de poco relieve que dan vuelta por los cuatro lados del sillar, es decir, que son piedras con molduración horizontal; las đimensiones de este tipo de sillares oscilan entre 42 a $48 \mathrm{~cm}$. de sección horizontal

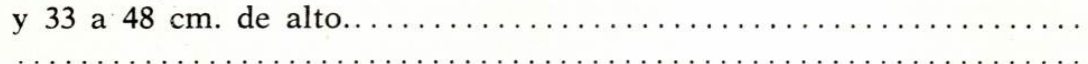

(18) J. C. Soto "Yapeyú", Año 1899

(19) En el patio del colegio se hallaba un cuadrante solar sobre una columna de piedra labrada de $1 / 2$ vara de alto, etcétera. 


\section{APÉNDICE:}

\section{FIGURA 17}
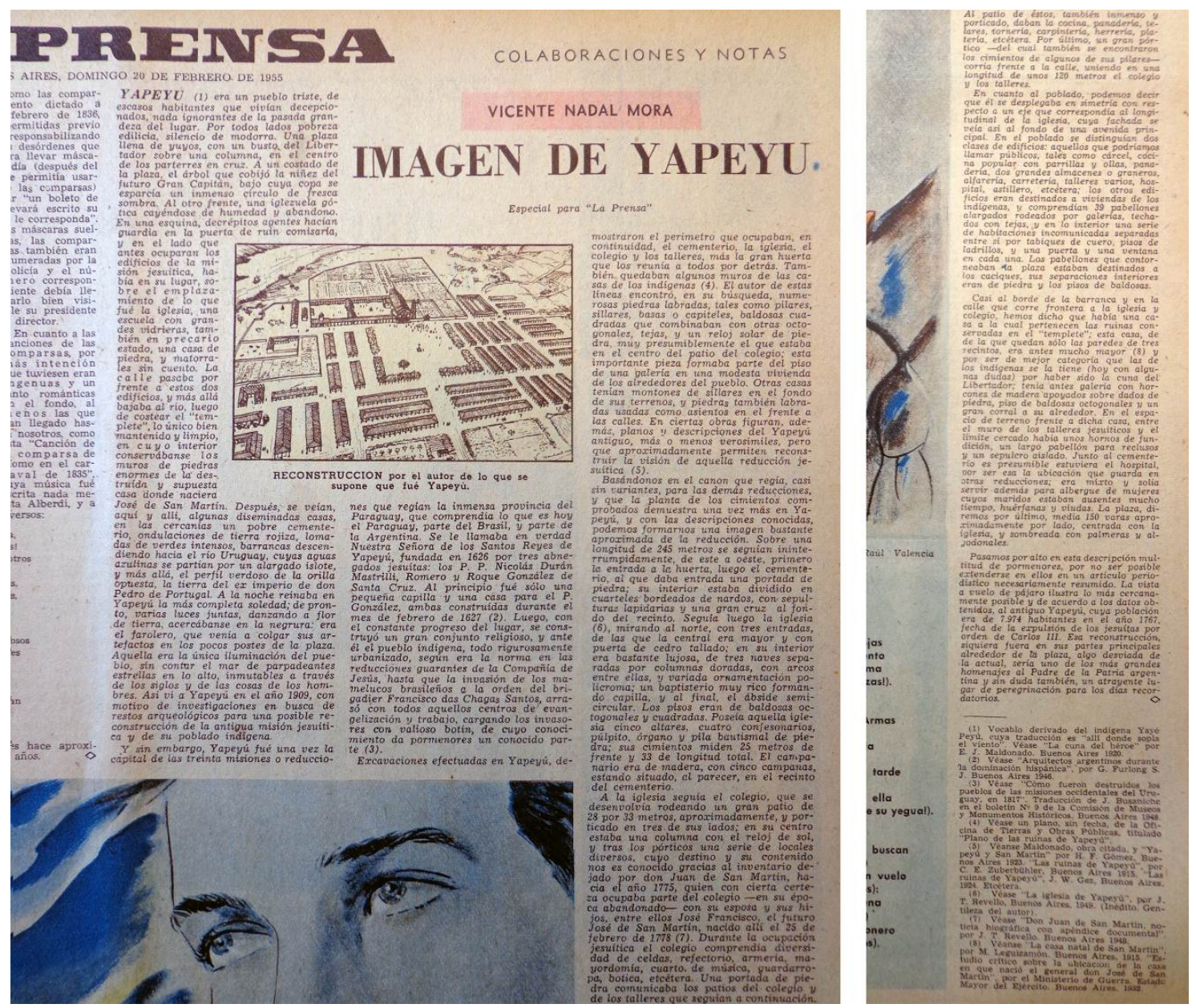

\section{La Prensa, 20 de Febrero 1955}

(Al final del primer párrafo donde dice “Así vi a Yapeyú en 1909...” debiera decir 1949, año en que realizó el viaje. En 1909 tenía 14 años y acababa de llegar a la Argentina). 
FIGURA 18

\section{$-352-$ \\ Presupuesto de Máximas para Yapeyú}

1) Restauración del pueblo antiguo.

Demoliciones edificios actuales ....... \$ $\$ 280.000$

Expropiación de terrenos ............ , 150.000

Recuperación de piedras ............, , 300.000

Construcción de 15 casas de indigenas .. „, 330.000

Arbolado y palmeras ............... , 180.000

Reconstrucción templo y misión ....... „2.200.000

Adaptación de la plaza y varios ......., , 260.000

$\$ 3.700 .000$

2) Formación del pueblo nuevo

Expropiación de terrenos .......... \$ 160.000

Construcción templo, escuela, correo, co-

misaría, municipalidad, etc. .............

Pavimentación y pbras exteriores

$\$ 2.880 .000$

3) Varios.

Excavaciones, reconocimientos, estudios, proyecto, dirección e inspección, $10 \%$.. \$ $\$ 657.000$

Imprevistos $5 \%$............... 378.500

Habilitación y diversos ............., , 384.500

$\$ 1.420 .000$

Total .......... $\overline{\$ 8.000 .000}$

ANIBAL F. IMBERT

José Luis Busaniche

\section{Presupuesto elaborado para el proyecto de ley}

(Boletín de la CNMyMH, 1948: 352) 
FIGURA 19

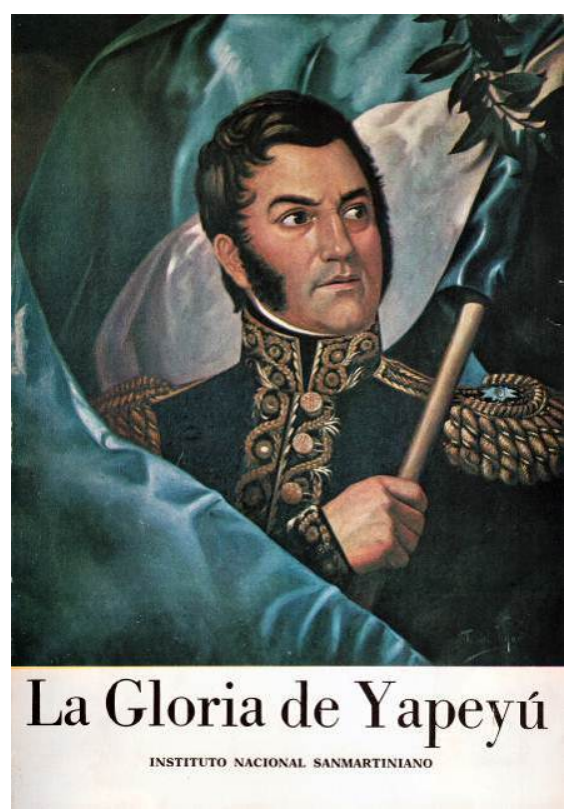

Tapa del libro (1978)

\section{Bibliografía}

AAVV (1973), Vicente Nadal Mora. Un alma sensible a la belleza, La Prensa Medica Argentina, Buenos Aires.

AAVV (1978), Museo de la cultura Jesuítica "Guillermo Furlong S.J." en Yapeyú, Departamento de Conservación del Patrimonio Arquitectónico, Facultad de Arquitectura, Universidad Nacional del Nordeste, Resistencia.

Castro, Osvaldo (1965), "Yapeyú, a vista de pájaro", en Estudios no. 562, Academia literaria del Plata, Buenos Aires, pp. 133-136.

Catoggio, María Mónica (1979), "Excavaciones: Yapeyúu, en revista DANA no. 7, Instituto Argentino de Investigaciones en Historia de la Arquitectura, Resistencia, pp. 13-18.

CNMyMH (1948), Boletín de la Comisión Nacional de Museos y Monumentos Históricos Año X no. 10 (memoria correspondiente al año 1947), CNMyMH, Buenos Aires.

CNMyMH (1952), Boletín de la Comisión Nacional de Museos y Monumentos Históricos Año XII no. 12 (memoria correspondiente al año 1949), CNMyMH, Buenos Aires, pp. 259-266.

Estado Mayor General del Ejército (1932), Estudio histórico sobre la ubicación de la casa en que nació el General José de San Martín, Talleres Gráficos del Instituto Geográfico Militar, Buenos Aires.

Furlong SJ, Guillermo (1962), Misiones y sus pueblos de guaraníes, Balmes, Buenos Aires.

Gómez, Hernán F. (1923), Yapeyú y San Martín, Librería Nacional J. Lajouane, Buenos Aires. 
Leguizamón, Martiniano (1915), La casa natal de San Martín, estudio crítico, Compañía Sudamericana de Billetes de Banco, Buenos Aires.

Lugones, Leopoldo (1904), El Imperio Jesuítico, Compañía Sudamericana de Billetes de Banco, Buenos Aires.

Maeder, Ernesto J. A. y Gutiérrez, Ramón (1994), Atlas histórico y urbano del nordeste argentino, Instituto de Investigaciones Geohistóricas, Resistencia.

Maeder, Ernesto J. A. y Gutiérrez, Ramón (2009), Atlas Territorial y Urbano de las Misiones Jesuíticas de Guaraníes. Argentina, Paraguay y Brasil, Junta de Andalucía, Sevilla.

Magaz, María del Carmen y Schávelzon, Daniel (1995), “La casa natal de San Martín”, en Revista Todo es Historia no. 337, Buenos Aires, pp. 82-95.

Maldonado, Eduardo (1918), La cuna del héroe, la casa natal del Libertador, J. Peuser, Buenos Aires.

Manzi, Francisco (1946), "Yapeyú: un poco de historia”, Boletín de la Comisión Nacional de Museos y Monumentos Históricos no. 8, CNMyMH, Buenos Aires, pp. 131-140.

Nadal Mora, Vicente (1955), “Imagen de Yapeyú”, en Diario La Prensa (20 de Febrero), Buenos Aires.

Nadal Mora, Vicente (1956), “Imagen de Yapeyú”, en Revista Estudios (junio), Academia Literaria del Plata, Buenos Aires.

Nadal Mora, Vicente (1978), "Estudio sobre Yapeyú”, en La Gloria de Yapeyú, Instituto Nacional Sanmartiniano, Buenos Aires, pp. 322-338.

Nadal Mora, Vicente (1995), Monumentos históricos de Misiones. San Ignacio Mini, edición facsimilar de la primera de 1955, Buenos Aires.

Schávelzon, Daniel (2008), Mejor olvidar: La conservación del patrimonio cultural argentino, De Los Cuatro Vientos, Buenos Aires.

Teruel, Ana A., Lacarrieu, Mónica B. y Jerez, Omar (2003), Fronteras, ciudades y estados, Tomo II, Alción Editora, Córdoba.

Torre Revello, José (1958), Yapeyu (Ensayo Histórico), Instituto Nacional Sanmartiniano, Buenos Aires.

Zuberbuhler, Carlos (1915), Las ruinas de Yapeyú, Imprenta Coni, Buenos Aires. 